\title{
THE CONTROL OF SULFUR CONTENT IN NICKEL-BASE, SINGLE CRYSTAL SUPERALLOYS AND ITS EFFECTS ON CYCLIC OXIDATION RESISTANCE
}

\author{
C. Sarioglu, C. Stinner, J. R. Blachere, N. Birks, F. S. Pettit, and G. H. Meier \\ Department of Materials Science \& Engineering \\ University of Pittsburgh \\ J. L. Smialek \\ NASA Lewis Research Center
}

\begin{abstract}
State-of-the-art superalloys are useful for high temperature applications, in large part, because they form protective alumina surface films by the selective oxidation of aluminum from the alloy. The adherence of the alumina to the alloy is crucial to maintaining oxidation resistance, particularly under thermal cycling conditions. It is now well established that small additions of reactive elements, such as yttrium, hafnium, and cerium, substantially improve the adherence of alumina films to alloy substrates. While the effects produced by the reactive elements are widely known the mechanisms whereby they improve adherence are not completely understood. Over the last fifty years a number of mechanisms have been proposed. However, it has recently become clear that a major effect of the reactive elements is to tie up sulfur in the alloy and prevent it from segregating to the alloy/oxide interface and weakening an otherwise strong bond.
\end{abstract}

This paper describes the results of a study of the control of sulfur content in alumina-forming nickel-base superalloys and NiAl by three methods:

1. Addition of Reactive Elements ( $\mathrm{Y}$ and $\mathrm{Hf})$.

2. Desulfurization in the solid state.

3. Desulfurization in the liquid state

Additionally, calculations have been performed to determine how much sulfur is available to segregate to the scale/alloy interface and how this quantity is influenced by the type and amount of reactive element in the alloy and the level to which the alloy is desulfurized. Finally, the results from experiments to desulfurize the alloys are described and cyclic oxidation measurements are used to evaluate the calculations.

\section{Introduction}

State-of-the-art superalloys and aluminide coatings are useful for high temperature applications, in large part, because they form protective alumina surface films by the selective oxidation of aluminum from the alloy. The adherence of the alumina to the alloy is crucial to maintaining oxidation resistance, particularly under thermal cycling conditions. It is now well established that small additions of reactive elements, such as yttrium, hafnium, and cerium, substantially improve the adherence of alumina films to alloy substrates [1]. While the effects produced by the reactive elements are widely known the mechanisms whereby they improve adherence are not completely understood. Over the last fifty years a number of mechanisms have been proposed. These include:

$$
\text { Superalloys } 1996
$$

Edited by R. D. Kissinger, D. I. Deye, D. L. Anton,

A. D. Cetel, M. V. Nathal, T. M. Pollock, and D. A. Woodford

The Minerals, Metals \& Materials Society, 1996
1. Reactive elements act as vacancy sinks to suppress void formation at the alloy/oxide interface $[2,3]$.

2. Reactive elements form oxide pegs at the alloy/oxide interface [4]

3. Reactive elements alter the growth mechanism of the oxide resulting in reduced growth stresses [5].

4. Reactive elements segregate to the alloy/oxide interface and form a graded seal [6] or otherwise strengthen the alloy/oxide bond [7].

5. Incorporation of the reactive element into the oxide increases its plasticity [8].

6. Reactive elements tie up sulfur in the alloy and prevent it from segregating to the alloy/oxide interface and weakening an otherwise strong bond $[9,10]$.

The importance of the latter mechanism has been illustrated in experiments where hydrogen annealing of nickel-base single crystals decreased the sulfur contents to very low levels and resulted in dramatic improvements in the adherence of alumina films to the alloys $[11,12]$.

This paper presents the results of studies of the effects of reactive element additions to alumina-forming single crystal $\mathrm{Ni}$-base superalloys and the effect of lowering the sulfur content of these alloys and $\mathrm{NiAl}$ on the oxide adherence.

\section{Experimental}

The alloys studied include three alumina-forming Ni-base single crystal superalloys (PWA 1480, PWA 1484, and PWA 1487) and equiatomic NiAl The single crystal alloys had an initial sulfur content of 8-10 ppm and were undoped (1480), doped with $0.1 \mathrm{Hf}$ (1484), and doped with $0.1 \mathrm{Hf}+0.1 \mathrm{Y}$ (1487). Additional polycrystalline alloys with compositions similar to PWA 1484 but containing 1, 3, and 45 ppm sulfur, provided by Howmet Corporation, were also studied. The NiAl contained $20 \mathrm{ppm}$ sulfur. Most specimens had approximate dimensions $1 \mathrm{~cm} \times 1 \mathrm{~cm} \times 1 \mathrm{~mm}$, however, additional specimens of selected alloys with thicknesses ranging from 0.3 to $3.0 \mathrm{~mm}$ were annealed in $\mathrm{Zr}$ gettered hydrogen for 100 hours at $1200^{\circ} \mathrm{C}$ to remove sulfur. All specimens were polished through 600 grit $\mathrm{SiC}$ paper, washed in soapy water, and rinsed in ethanol prior to oxidation or hydrogen annealing. Hydrogen annealed specimens were oxidized with no further surface treatment. Cyclic oxidation was performed in air at $1100^{\circ} \mathrm{C}$ with one cycle consisting of 45 minutes in the hot zone and 15 minutes cooling above the furnace. Selected alloys were also oxidized isothermally in air at $1100^{\circ} \mathrm{C}$. The oxidized specimens were examined normal to the surface and in cross-section using optical and scanning electron metallography. 
The residual stress in the oxide scale was measured at room temperature via the classical $\operatorname{Sin}^{2} \Psi$ method[13] using a Philips $\mathrm{X}$ 'pert diffractometer fitted with an open Eulerian cradle and parallel beam optics with a Ni-filter [14]. The X-ray source was a point source with a $\mathrm{Cu}$ target. The lilling method combined with glancing incident angle ("Thin Film geometry") was employed to measure strain/stress in the $\alpha$-alumina layer. The geometrical set up of this technique is schematically shown in Figure 1. This technique was chosen because this setup provides greater intensity of the

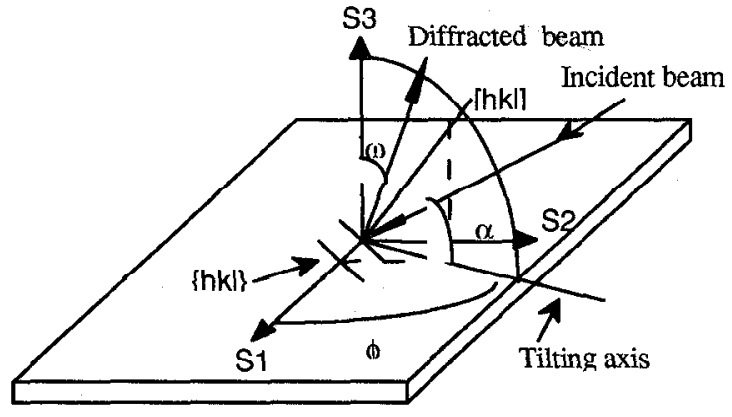

Figure 1: Schematic drawings of the set up of the Tilting technique

diffracted $x$-rays from the alumina layer as a result of increase in the interaction volume of the $\mathrm{x}$-rays in the alumina layer. The specimen is tilted around an axis ( parallel to the surface of the specimen and in the diffraction plane) which is the intersection of the diffraction plane with the surface of the specimen. The (113) reflection of the $\alpha$-alumina was scanned with a fixed incidence of $\alpha=1.75^{\circ}$ for the tilt angles $\psi=0^{\circ}, 28^{\circ}$ and $33^{\circ}$. $\psi=0$ when the specimen normal is in the diffraction plane (Figure 1). The tilt angles were selected when (113) diffraction lines could be measured. With this type of geometry, $\psi$ is not the angle of the tilt of the diffraction planes since these planes are inclined with respect to the surface of the specimen. The angle $\psi_{2}$ used in the $\operatorname{Sin}^{2} \psi$ plots is measured between the normal to (113) planes and the normal to the specimen surface. It is given by equation (1) [15].

$$
\operatorname{Cos} \psi_{2}=\operatorname{Cos} \omega \operatorname{Cos} \psi
$$

in which $\omega=\theta_{\mathrm{b}}-\alpha . \theta_{\mathrm{b}}$ is the bragg angle for the (113) reflection. The absorption correction of the $\mathrm{x}$-ray intensities is carried out by using the equation in reference 15 . The line positions in the $2 \theta_{b}$ scan were determined by fitting a parabola to the top of the peak [16].

\section{Results And Discussion}

\section{Single Crystal Alloys}

The results of cyclic oxidation experiments for the Ni-base single crystal alloys at $1100^{\circ} \mathrm{C}$ are presented in Figure 2. The oxidation resistance of the untreated alloys is in the order $1487>1484>1480$ which suggests that doping with $0.1 \mathrm{Hf}$ improves adherence but that combined doping with $0.1 \mathrm{Hf}+0.1 \mathrm{Y}$ is more effective. Unfortunately an alloy doped only with $Y$ was not available.

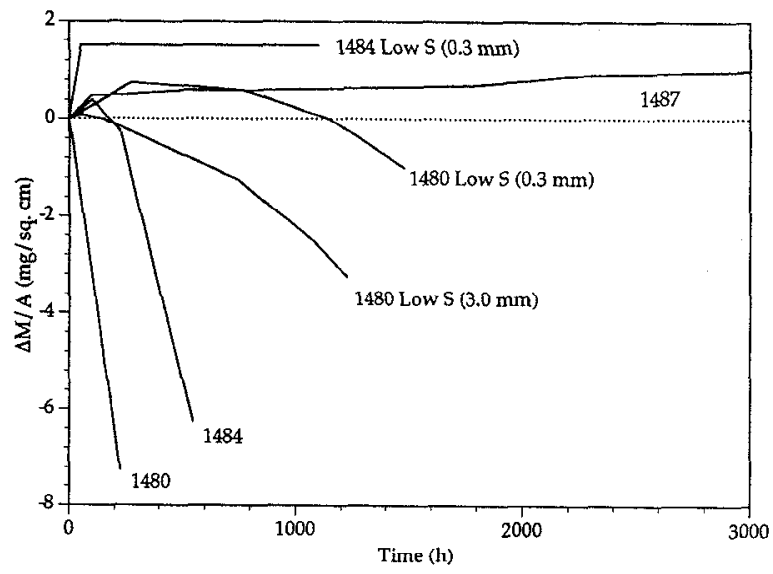

Figure 2: Cyclic oxidation kinctics in air at $1100^{\circ} \mathrm{C}$ (1hour cycles) for $1480,1484,1487$, desulfurized 1484 , and desulfurized 1480 .

Sulfur removal improved the cyclic oxidation resistance of both 1480 and 1484. These results support the observations that sulfur removal improves the alumina adherence to alloys which do not contain reactive elements (1480). However, the improvement for 1484, which contains $\mathrm{Hf}$, indicates that the sulfur removal somehow makes the Hf more effective. Whether this effect will occur for an alloy containing $\mathrm{Y}$ is not yet clear.

Figure 2 also indicates a dependence on specimen thickness for the desulfurized PWA 1480. The hydrogen anneal improved the adherence for the $3.0 \mathrm{~mm}$ thick specimen but not to the extent for the $0.3 \mathrm{~mm}$ thick specimen. This implies a limitation on the section thickness which can be desulfurized in the solid state. This problem has been addressed by Smialek and coworkers [17,18]. For thin specimens the average sulfur content, $C_{S}$, may be calculated as a function of time during hydrogen annealing from

$$
\mathrm{C}_{\mathrm{S}} / \mathrm{C}_{\mathrm{S}, \mathrm{i}}=\left(8 / \pi^{2}\right) * \exp \left(-\pi^{2} \mathrm{D}_{\mathrm{S}} \mathrm{t} / \mathrm{L}^{2}\right)
$$

where: $\mathrm{C}_{\mathrm{s}, \mathrm{i}}$ is the initial sulfur content.

$D_{S}$ is the sulfur diffusivity in the alloy.

$t$ is the annealing time.

$\mathrm{L}$ is the specimen thickness.

Equation (2) will be valid as long as the desulfurization process is diffusion controlled. Taking an initial sulfur content of $10 \mathrm{ppm}$ and approximating $D_{S}$ as that in pure $\mathrm{Ni}[19]$ one calculates from Eqn. (2) 
that the $100 \mathrm{hrs}, 1200^{\circ} \mathrm{C}$ anneal should lower the sulfur content to 3 ppm for a $3.0 \mathrm{~mm}$ thick specimen and to $10^{42} \mathrm{ppen}$ for a $0.3 \mathrm{~mm}$ thick specimen. While the latter number is clearly unrealistic in that diffusion control will not persist to such low concentrations, it indicates that the thinner specimen would be desulfurized to a very low level. On the other hand, the thicker specimen contains enough residual sulfur to segregate and degrade adherence of the alumina scale. Smialek et al [18] have considered the adsorption behavior of S to a Ni surface as a function of $C_{S}$ and combined this with Eqn. (2) to express the relationhip between initial sulfur content and the bydrogen annealing conditions rexuired to lower the sulfur content to a level that will result in some number of monolayers of sulfur, $\mathrm{N}_{\mathrm{m}}$ during saturation of the surface:

$$
\mathrm{C}_{\mathrm{s}, i}=\left(8.27 \times 10^{2} \mathrm{gm} / \mathrm{cm}^{2}\right) *\left(\mathrm{~N}_{m} \mathrm{~A} / \mathrm{W}\right) *\left(\pi^{2} / 8\right) * \exp \left(\pi^{2} \mathrm{D}_{\mathrm{si}} \mathrm{t} / \mathrm{L}^{2}\right)
$$

where: $\mathrm{C}_{\mathrm{S}, i}$ is expressed in ppmw,

$A$ is the specimen surface area in $\mathrm{cm}^{2}$.

$W$ is the specimen mass in $\mathrm{gm}$.

Taking one monolayer $\left(\mathrm{N}_{m}=1\right)$ as the amount of segregation necessary to degrade adtherence allows calculation of the annealing time required at $1200^{\circ} \mathrm{C}$ to adequately desulfurize the specimens. These times are $2.6 \mathrm{~h}$. for the $0.3 \mathrm{~mm}$ thick specimen and $492 \mathrm{~h}$, for the $3.0 \mathrm{~mm}$ thick specimen. These times indicate that substantially longer hydrogen annealing would be required for the thicker specimen while the $0.3 \mathrm{~mm}$ specimen would be adequately desulfurized after $100 \mathrm{~h}$. However, it is interesting to note that the $0.3 \mathrm{~mm}$ thick specimen of 1480 still did not have the cyclic oxidation resistance exhibited by the $0.3 \mathrm{~mm}$ thick specimen of hydrogen-annealed 1484 which was doped with Hf. A similar result has also been reported for CMSX-4 which is also doped with Hf $[20]$. This suggests that the removal of sulfur makes the Hf more effective. The unannealed 1487 which contained $\mathrm{Hf}+\mathrm{Y}$ also showed better cyclic oxidation resistance than the annealed 1480. This resuit suggests $\mathrm{Y}$ is more effective than $\mathrm{Hf}$ as a "sulfur getter" or may provide some benefit to alumina adherence beyond sulfur-gettering and that optimum performance may be achieved by combining desulfurization and reactive-element doping.

\section{Polyctystalline Alloys}

The starting microstructures of the alloys with the varying sulfur levels were similar. They exhibited a dendritic $\gamma+\gamma^{2}$ mictostructure with a grain size varying from 50 to $100 \mu \mathrm{m}$. Small amounts of a Ta-rich phase, which was not present in single crystal 1484, were identified along the grain boundaries by EDS.
The isothermal oxidation rates of the single crystal and polycrystalline alloys were all similar at $1100^{\circ} \mathrm{C}$ yielding parabolic rate constants on the onder of $5 \times 10^{\mathrm{th}} \mathrm{g}^{2} / \mathrm{cm}^{4} \mathrm{~s}$. However, on cooling after 168 hours of oxidation the scale spalled completely from the $45 \mathrm{ppm} \mathrm{S}$ alloy and spalled partially from the $8 \mathrm{ppm} \mathrm{S}$ single crystal. The scale remained completely adherent to the 1 and $3 \mathrm{ppm} S$ alloys. The surface and cross-section of the $3 \mathrm{ppm} \mathrm{S}$ alloy are shown in Figure 3. Transient oxidation resulted in thicker oxide on certain grains and dendrites (e.g. dark grains in the SEM surface micrograph) as opposed to others (tight

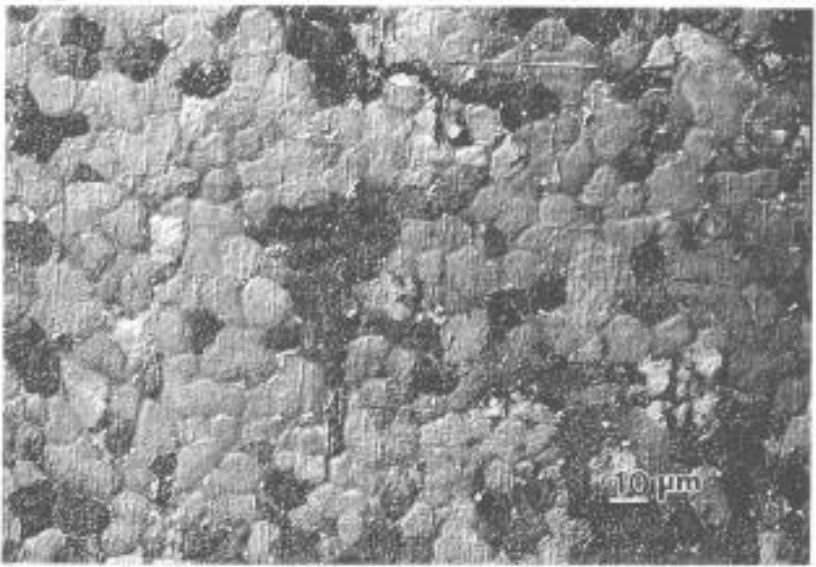

A.

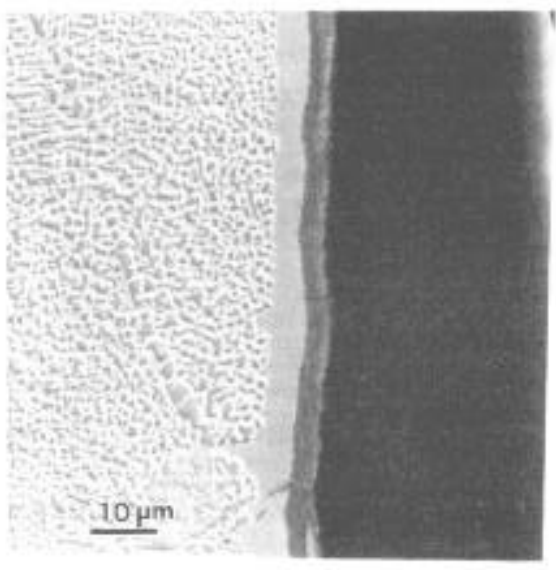

B.

Figure 3: SEM (SEI) surface (A) and cross-section (B) of a polycrystalline alloys (3ppm sulfur) after oxidation at $1100^{\circ} \mathrm{C}$ in air for 168 hours

grains). Bright spots in the SEM micrograph of the surface were Tarich oxides, as indicated by EDS. These apparently formed by the rapid oxidation of the Ta-containing phase on the grain boundaries. The cross-section indicates an adherent oxide in contact with an Aldepleted layer in the alloy along a wavy interface. The Al-depleted layer, which was observed for all the alloys, was indicated by XRD to contain only $\gamma \quad \mathrm{X}$-ray diffraction and EDS indicated that the scale consisted of continuous $\alpha-\mathrm{Al}_{2} \mathrm{O}_{4}$ covered with a layer containing $\mathrm{NiO}$, $\mathrm{Cr}_{2} \mathrm{O}_{3}, \mathrm{Ni}(\mathrm{ALCr})_{2} \mathrm{O}_{4}$, and $\mathrm{NiTa}_{2} \mathrm{O}_{6}$ for all the alloys. The surface and cross-section of the $45 \mathrm{ppm} \mathrm{S}$ alloy are presented in Figure 4. The oxide has spalled from a large fraction of the specimen area during cooling and spalled oxide fragments are seen lying on the surface. The cross-section shows that the scale is separated from the alloy even in areas where it has not completely spalled. 
Figure 5 shows the results of cyclic oxidation experiments on 1484 alloys with various sulfur contents at $11000^{\circ} \mathrm{C}$. These data show that,

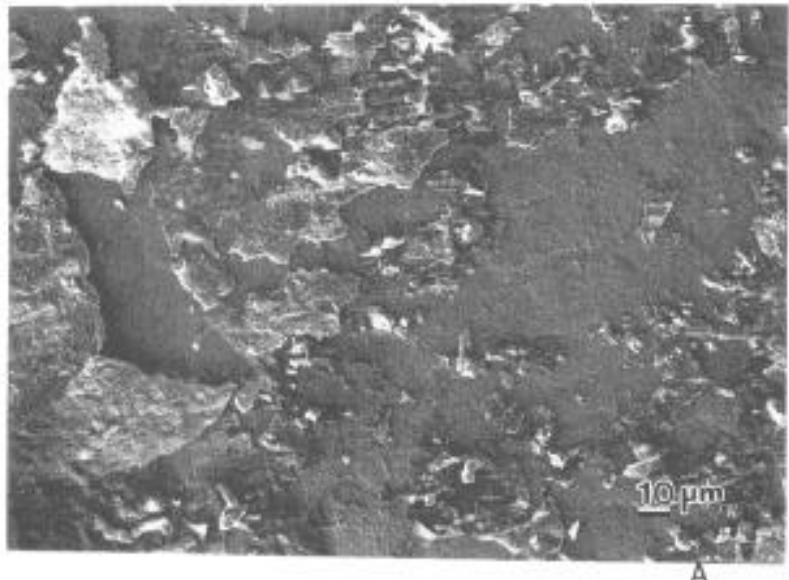

A.

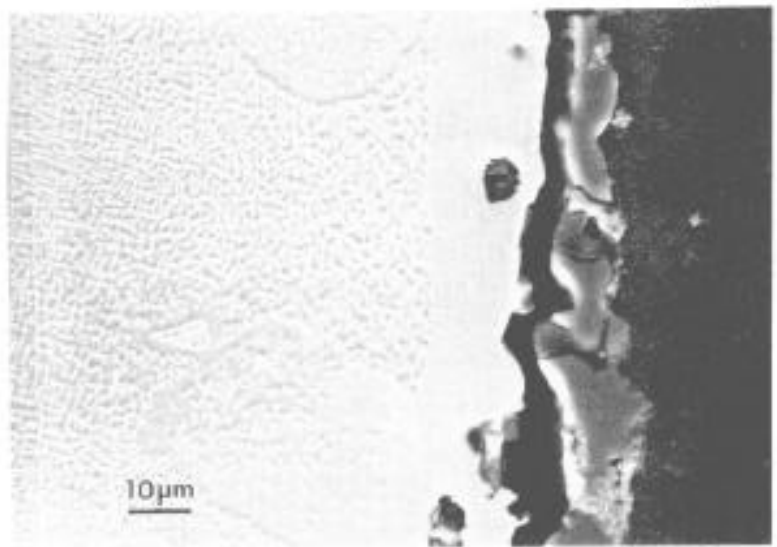

B.

Figure 4: SEM (SEI) surface (A) and cross-section (B) of a polycrystalline alloy ( $45 \mathrm{ppm}$ sulfur) after oxidation at 1100 ${ }^{\circ} \mathrm{C}$ in air

for this alloy, there is a critical sulfur content between 3 and 8 ppm below which adherent scales are formed. Comparison with the data for PWA 1480, in Figure 2, indicates that either the 0.1 wt\% $\mathrm{Hf}$ in the polycrystalline specimens containing 1 and $3 \mathrm{ppm} \mathrm{S} \mathrm{lowers} \mathrm{the} \mathrm{content}$ of sulfur which is free to diffuse to the alloy/oxide interface to below $0.1 \mathrm{ppm}$, or it provides a beneficial effect in addition to sulfur-gettering. Furthermore, the data for PWA 1487 (containing approximately 10 ppm S), in Figure 2, indicate that the combined presence of 0.1 wt $\mathrm{HI}$ and 0.1 wt $\% \mathrm{Y}$ is able to mitigate the effects of higher sulfur contents. These results are significant in that they indicate that:

- the sulfur content must be reduced below $0.1 \mathrm{ppm}$ if long-term scale adherence is to be achieved without the use of reactive elements and

- that, when reactive elements are used, the amount of sulfur which can be tolerated varies with the amount and type of reactive element used.
These two points will be discussed more quantitatively in the section on mechanisms.

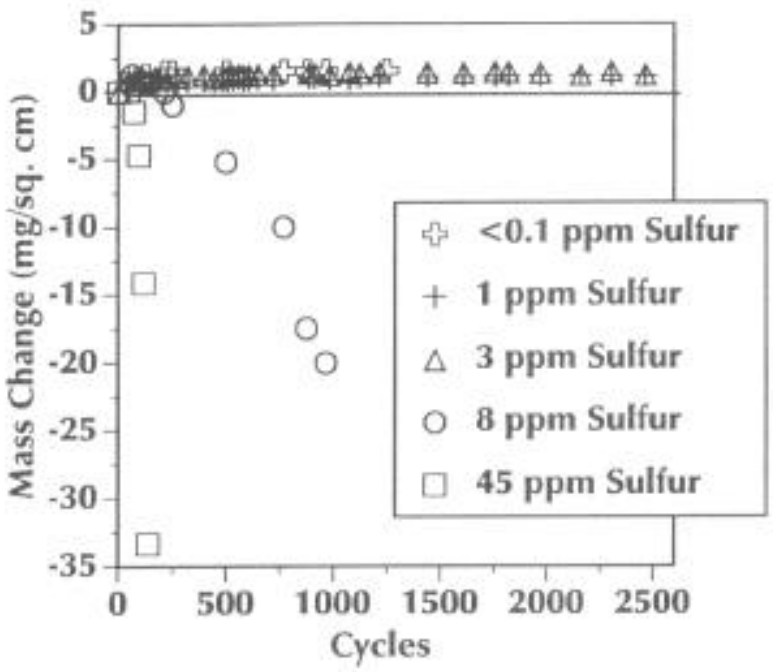

Figure 5: Cyclic oxidation kinetics in air at $1100^{\circ} \mathrm{C}$ ( 1 hour cycles) for polycrystalline alloys with different sulfur levels and desulfurized $1484(<0.1 \mathrm{ppm}$ S).

Residual stress in the $\alpha$-alumina layer underneath the transient oxide layer on a polycrystalline alloy containing $1 \mathrm{ppm}$ sulfur after 24 hours oxidation at $1100^{\circ} \mathrm{C}$ in air was measured by XRD at room temperature. Figure 6 shows the oxide scale consisting of an $\alpha$-alumina layer ( $2 \mu \mathrm{m}$ thick) between a transient oxide layer and an Al-depleted substrate $(\gamma)$ layer. The oxide layer was adherent to the substrate after cooling to room temperature (there was no noticeable oxide spallation).

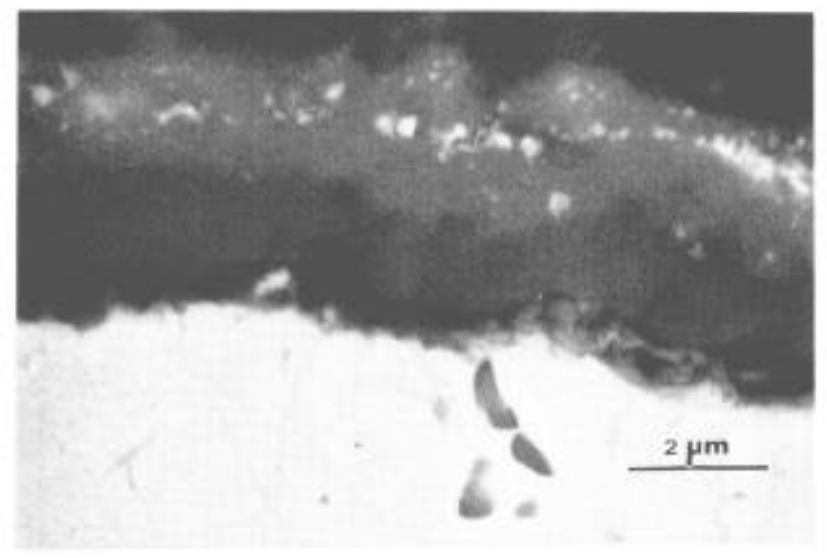

Figure 6: SEM (BEI) cross-section micrograph of a polycry stalline alloy ( $1 \mathrm{ppm}$ sulfur) after isothermal oxidation at $1100^{\circ} \mathrm{C}$ in air for 24 hours.

Assuming a biaxial ( an isotropic ) stress-state $\left(\sigma_{11}=\sigma_{22}=\sigma, \sigma_{39}=0\right.$, $\sigma_{12}=\sigma_{23}=\sigma_{13}=0$ ) and a homogeneous elastic medium, the strain in a 
direction $\phi$ along the surface of the film for an inclination (tilt) $\psi_{2}$ of the selected $(h, k, l)$ plane with respect to the surface of the film is:

$$
\left(\varepsilon_{3}\right)_{\psi_{2}}=\frac{\mathrm{d}_{\psi_{2}}-\mathrm{d}_{0}}{\mathrm{~d}_{0}}=\frac{1+\mathrm{v}}{\mathrm{E}} \sigma \sin ^{2} \psi_{2}-\frac{2 \mathrm{v}}{\mathrm{E}}(\sigma)
$$

Here, $\left(\varepsilon_{3}\right) \psi_{2}$ is the average strain in the direction normal to the diffracting planes (113) which have an angle $\psi_{2} ; \mathrm{d}_{\psi}$, is the measured $d$-spacing of (113) planes and $d_{0}$ is the unstrained value; the stress $\sigma$ is the normal stress in the plane parallel to the surface of the film, and $v$ and $E$ are the Poisson's ratio and Young's modulus of the film, respectively $[13,16,21]$. The data of Figure 7 were obtained from the value of $o=0$ with stage tilt $(\psi), 0^{\circ}, 28^{\circ}$ and $33^{\circ}$. Because of the strong texture of the alumina layer, a limited number of peaks is obtained as the specimen is tilted. Futher experiments

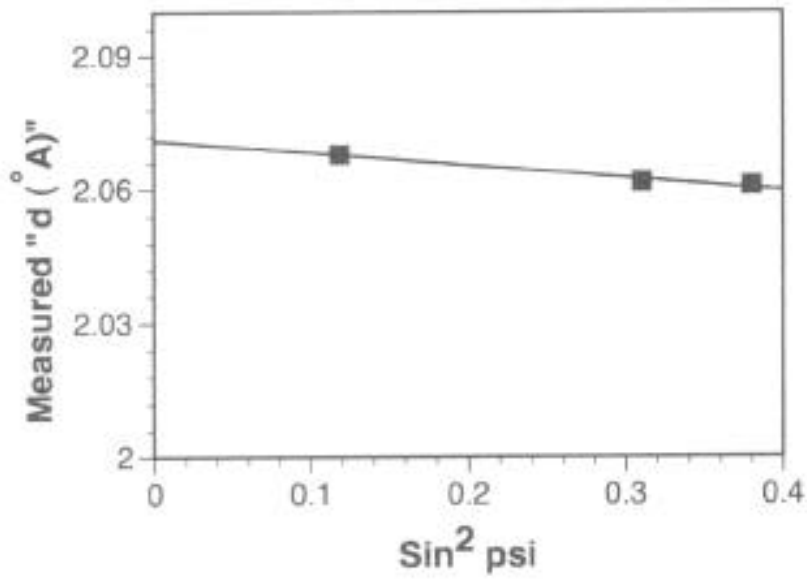

Figure 7: Plot of measured d-spacings for the (113) plane of $\alpha$-alumina on polycrystalline alloy after isothermal oxidation at $1100^{\circ} \mathrm{C}$ in air for 24 hours.

and more detailed analysis of the effect of texture on these data are underway, Nevertheless, the data showed a linear change indicating that the assumptions for equation (4) are satisfied and the stress gradient through the alumina layer is not significant ( a stress gradient leads to curvature in the plot). The stress is obtained from the slope of the plot of $\left(d_{\psi_{2}}-d_{0}\right) / d_{0}$ or $d_{\psi} v_{2} \sin ^{2} \psi_{2}$. The calculated value is $-4051 \mathrm{MPa}$ and the calculated strain in the alumina layer parallel to the surface of the specimen is $-0.83 \%$. The thermal stress in the alumina layer is calculated from the thermal expansion coefficients $[22,23]$ and elastic moduli of the substrate and alumina [24], and the poisson ratio of alumina [24] as -3857 $\mathrm{MPa}$. The range of uncerainty in the calculation of the thermal and measured stresses is approximately $15 \%$. Luthra and Briant [25] reported that the strain in the alumina layer formed on NiCrAIY and NiCoCrAlY at $1150-1225^{\circ} \mathrm{C}$ in air for $72-96$ hours was negligible (compressive strain) although scattering in the data was significant. C.Diot et. al. [23] reported that the residual stress in the alumina layer formed on a NiCoCrAlY coating at $1100^{\circ} \mathrm{C}$ for 300 hours was calculated as $-5700 \mathrm{MPa}$
Residual stresses measured in the current study are almost equal to the calculated thermal stresses suggesting minor growth stresses or relaxation of the growth stresses. The alloy containing 1ppm sulfur withstood high residual stresses during cooling indicating that the alumina/ alloy interface is inherently strong (adherent) while the alloy containing $8 \mathrm{ppm}$ and $45 \mathrm{ppm}$ sulfur showed extensive spallation during cooling indicating that sulfur weakened an otherwise strong interface. These results support the mechanism $[9,10]$ by which the adherence of the alumina to the substrate is improved by addition of reactive elements such as $\mathrm{Hf}$, and $\mathrm{Y}$.

Mass Change/Area $\left(\mathrm{mg} / \mathrm{cm}^{2}\right)$

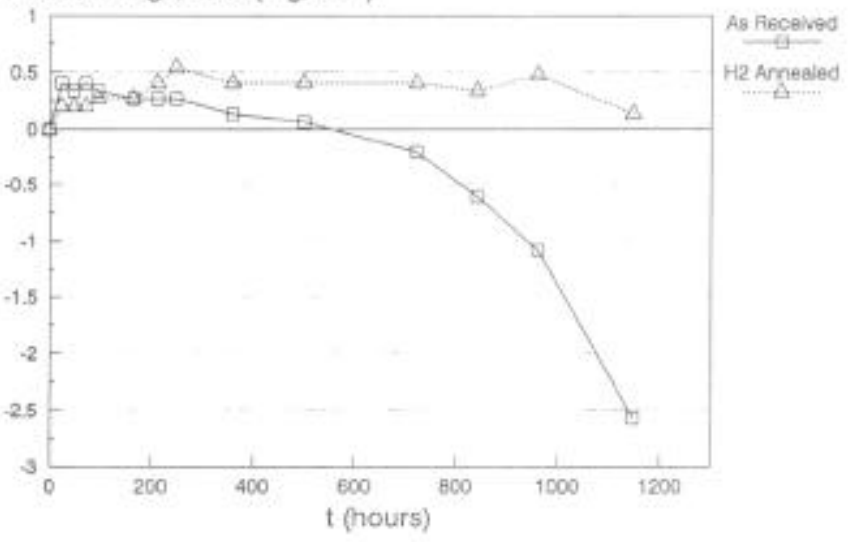

Figure 8: Cyclic oxidation kinetics in air at $1100^{\circ} \mathrm{C}$ ( 1 hour cycles) for as-received and hydrogen annealed $\mathrm{NiAl}$.

\section{NiAl}

Figure 8 shows the effect of desulfurization on the cyclic oxidation of NiAl. The as-received specimen contained $20 \mathrm{ppm} \mathrm{S}$ and exhibited extensive scale spallation. The sulfur content of the hydrogen-annealed specimen was estimated from Eqn. (2) to be on the order of $0.1 \mathrm{ppm}$ and this alloy exhibited a substantial improvement in cyclic oxidation resistance.

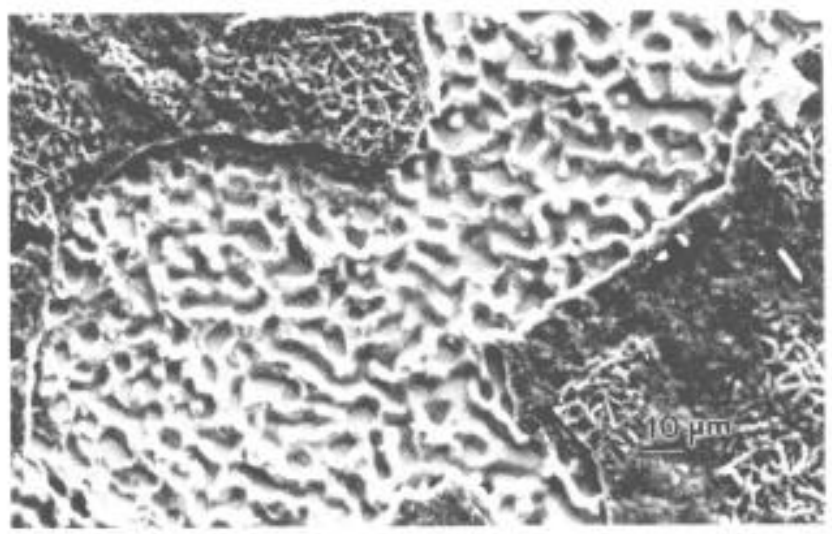

Figure 10: SEM (SEI) surface micrograph of asreceived $\mathrm{NiAl}$ isothermally oxidized at $1100^{\circ} \mathrm{C}$ in air for one week illustrating void formation. 


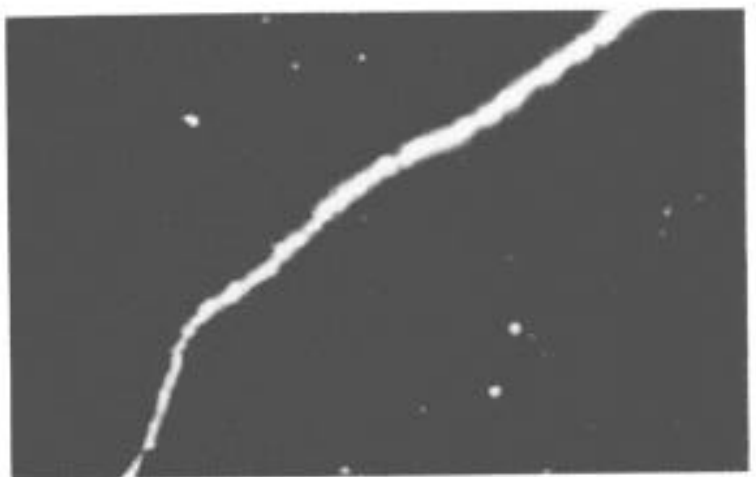

A.

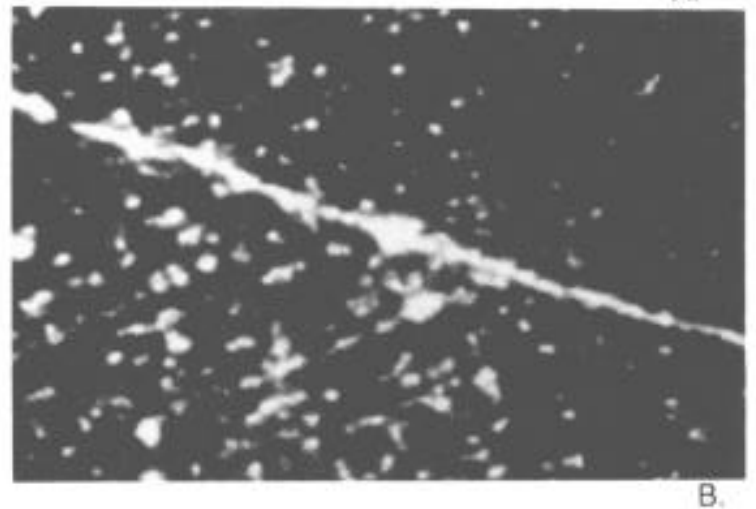

Figure 9: Polarized light optical surface micrographs of NiAl isothermally oxidized for 48 hours at $1100^{\circ} \mathrm{C}$. A. hydrogen annealed. B. as-received.

The hydrogen annealing also affected the morphology of the alloy/oxide interface. Figure 9 shows polarized light micrographs of the surfaces of as-received and hydrogen- annealed NiAl after isothermal oxidation at $1100^{\circ} \mathrm{C}$ for 48 hours. The bright areas are voids beneath the $\alpha-\mathrm{Al}_{2} \mathrm{O}_{3}$ scale at the alloy/oxide interface. Voids have coalesoed along grain boundaries in the $\mathrm{NiAl}$ in both specimens but there is profuse void formation over the grains in the as-received specimen whereas there are very few for the hydrogen annealed specimen. Figure 10 shows more detail of the voids in a spalled area of the as-received material after isothermal oxidation at $1100^{\circ} \mathrm{C}$ for one week. It is clear that most of the surface was separated from the scale by voids. Figure 11 shows one of the few spalled regions on the hydrogen-annealed specimen after the same oxidation treatment. The trench that formed on a grain boundary is evident, however, there are only a few voids within the adjacent grains. Most of the depressions on the surface of the grains are the imprints of oxide grains. The above results indicate that sulfur has detrimental effects on oxide adherence to NiAl, as it does to superalloys, and that contol of sulfur in diffusion aluminide coatings can be expected to increase coating life.

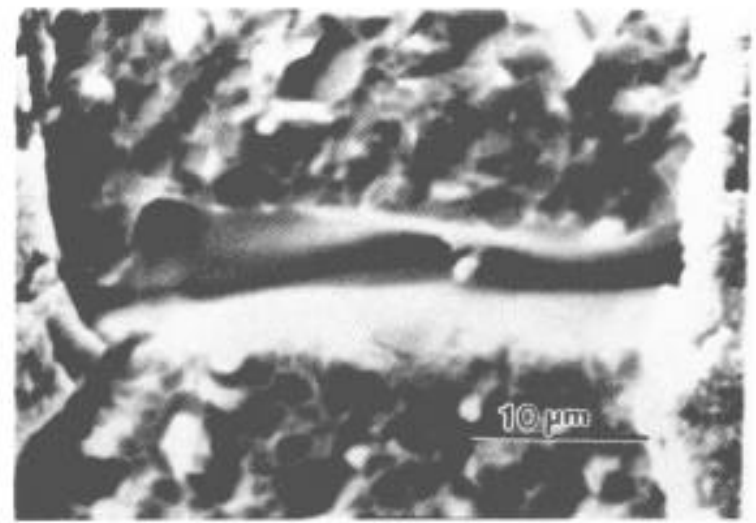

Figure 11: SEM (SEI) surface micrograph of hydrogen annealed $\mathrm{NiAl}$ isothermally oxidized at $1100^{\circ} \mathrm{C}$ in air for one week illustrating void formation at a grain boundary.

\section{Mechanisms}

The above results clearly indicate that removing sulfur improves the adherence of the alumina scales to both Ni-base superalloys and NiAl. This also supports the proposals in previous studies $[9-12,17,18,20]$ that the improvements in scale adherence produced by reactive element additions, e.g. Figs. 2 and 5, are, at the very least, partly the result of sulfur being combined with the reactive ekment so that it cannot diffuse to the alloy oxide interface or enter the scake. However, the question remains as to how the sulfur actually degrades oxide adherence. Hou and Stringer [26] report Auger electron spectroscopy observations of sulfur segregation at in-tact FeCrAV/alumina interfaces and suggest that sulfur weakens the bond between the alloy and oxide. Grabke et al [27] argue that sulfur can only segregate to an alloy/gas interface and that, since sulfur lowers the surface free energy, it causes voids to grow along the alloy/oxide interface. No measurements of sulfur segregation were made in the present study but Figure 10 clearly shows that woids separated much of the scale from NiAl containing 20 ppm $\mathrm{S}$ whereas there are relatively few voids on desulfurized NiAl. Fig. 11, except at grain boundaries. These observations are more consistent with the void growth mechanism. However, the fact that desulfurization prevents voids, means that reactive elements acting as "vacancy sinks" $[2,3]$ are not necessarily required to suppress interface voids. As long as sulfur is not free(or available) to diffuse to the alloy/oxide interface other sites in the alloy, such as grain boundaries and dislocations, become more effective sinks than the alloy/oxide interface.

The work of Smialek et. al. $[17,18]$ has pointed to a critical sulfur content which must be achieved by desulfurization in order to achicve good adherence. If the major effect of reactive element additions is to tie up sulfur the same concept should apply to doped alkys. The effect of sulfide stability on surface adsorption of sulfur has been analyzed by Luthra and Briant [25] for binary M-S alloys and they indicated how their treatment could be extended to reactive element-doped alloys. However, the activity coefficients and surface free energies required for the calculations are generally not available. The analysis used here will extrapolate existing solubility product data to indicate how reactive element additions affect the amount of sulfur available for transport to the alloy/oxide interface. 
The equilibrium between a reactive element sulfide (MS) and the elements in solution in the alloy is shown schematically in Figure 12 and may be represented by

\section{Solubility Product of Reactive Metal Sulfides}

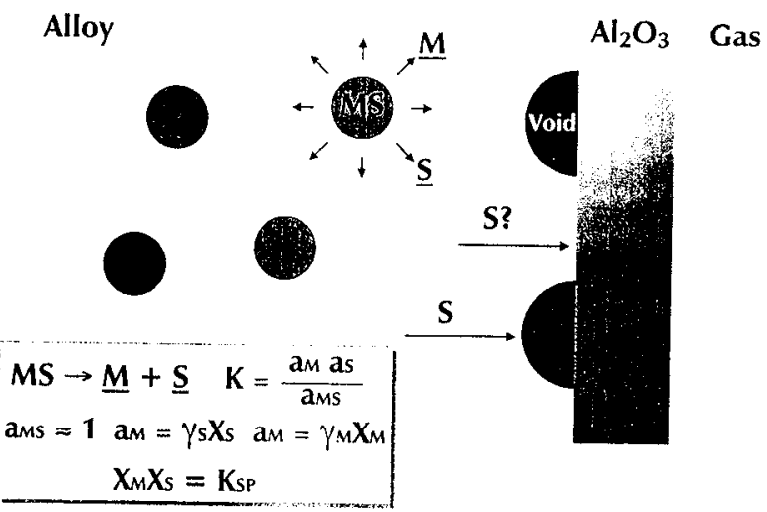

Figure 12: schematic illustration of the equlibrium between a reactive element sulfide (MS) and the elements in solution.

$$
\operatorname{MS}(s)=\underline{M}+\underline{S}
$$

If the activity of the sultide is taken as unity the activity coefficients of the elements in solution (taken here as independent of concentration) can be combined with the equilibrium constant for Eqn. 5 to yield a solubility product for MS.

$$
K_{S P}=C_{M}^{\mathrm{Resid}} \chi C_{S}^{\mathrm{Re} s i d}
$$

Here $C_{M}^{\text {Resid }}$ refers to the concentration of reactive element (in at $\%$ or wt.\%) left in solution and will be given by

$$
C_{M}^{\mathrm{Re} s i d}=C_{M}^{o}-C_{M}^{M S}
$$

where $C_{M}^{o}$ is the total reactive clement content of the alloy and $C_{M}^{M S}$ is the amount of reactive element tied up in the sulfide. Similarly,

$$
C_{S}^{\mathrm{Re} s i d}=C_{S}^{o}-C_{S}^{M S}
$$

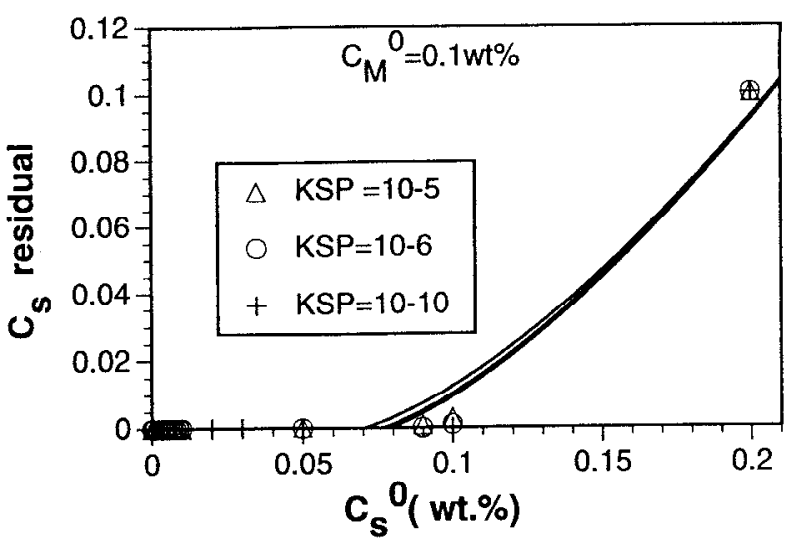

A.

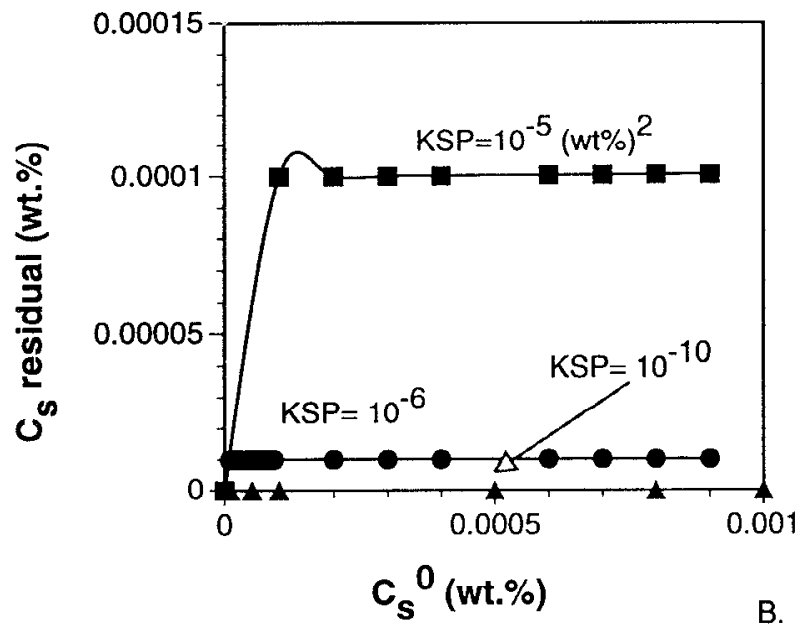

Figure 13: The effect of varying solubilty product of sulfide (MS) on residual sulfur content in solution. A: greater values of $\mathrm{C}_{S}{ }^{0}$. B. smaller values of $\mathrm{C}_{\mathrm{S}}{ }^{0}$

where $C_{S}^{o}$ is the total sulfur content of the alloy and $C_{S}^{M S}$ is the amount of sulfur tied up in the sulfide. Note that $C_{S}^{M S} \approx C_{M}^{M S}$. Solubility products for sulfides in the alloys under study are not available. However, the use of representative values allows trends to be determined as indicated in Figure 13. (Note that sulfur concentrations have been convertcd to wt.\%.) A $K_{S P}$ value of $1.4 \times 10^{-6}(\mathrm{at} \%)^{2}$ is reported for TiS at $1100^{\circ} \mathrm{C}$ in austenitic $\mathrm{Fe}$ [28] (which might approximate the solubility of TiS in a superalloy). The value of $10^{-10}(\text { at } \%)^{2}$ might approximate the dissolution of YS which is a much more stable sulfide than TiS. The other values were chosen to show the effect of varying the solubility product. The trends indicated in Figure 13 and 14 are:

i. The residual sulfur content decreases with the amount of reactive element added.

ii. The residual sulfur content decreases with increased stability of MS i.e. a decrease in $\mathrm{K}_{\mathrm{sp}}$

iii. The residual sulfur content is essentially independent of the initial sulfur content between two critical values of $C_{s}^{o}$.

The two critical values of $\mathrm{C}_{s}{ }^{0}$ mentioned in item (iii) are a low value, below which the sulfur activity is too low to form a sulfide, and a high 
value, above which there is more than the stoichometric amount of sulfur to react with all the reactive element present.
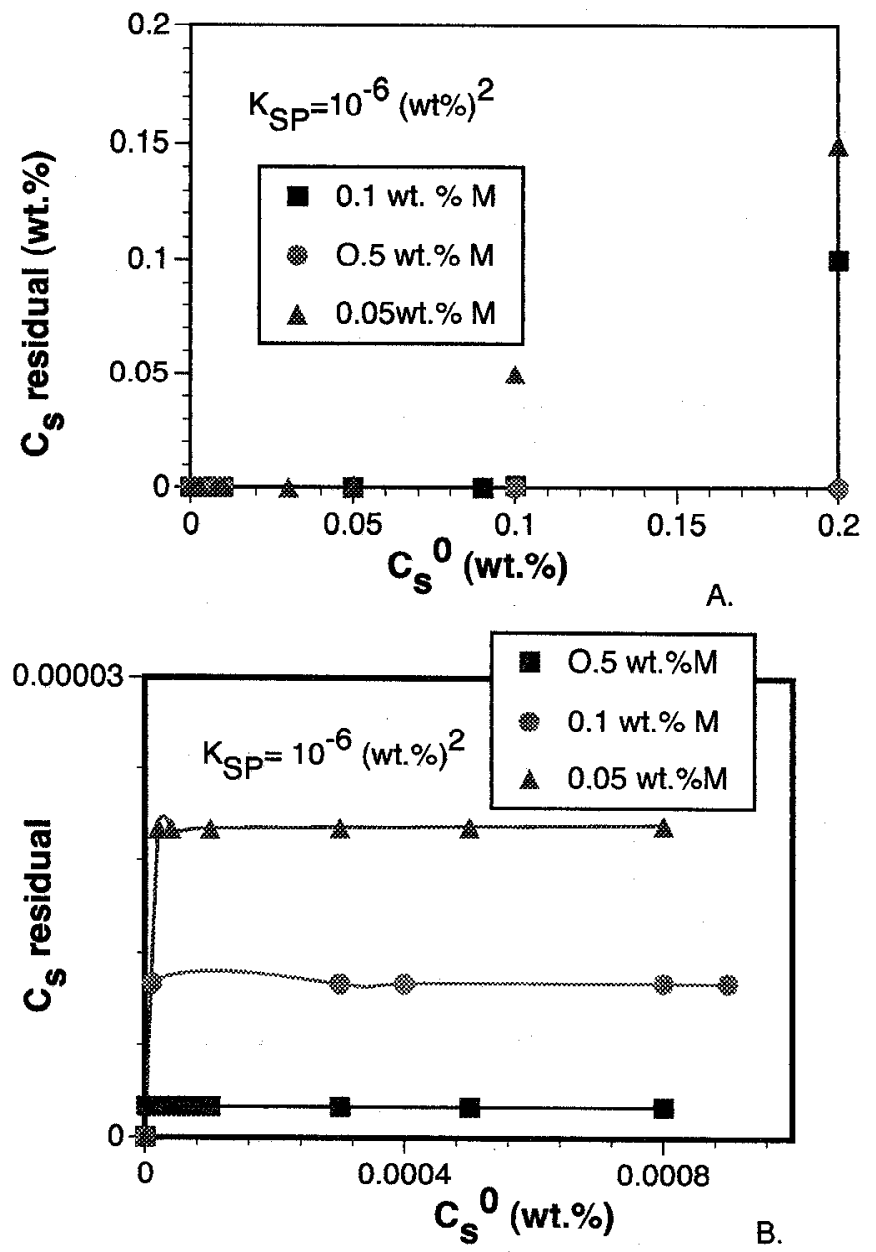

Figure 14: The effect of varying the concentration of reactive element added to an alloy on residual sulfur content in solution. A. For grcater values and (B) smaller values of $\mathrm{C}_{s}{ }^{0}$

Some of the above results may be qualitatively explained using Figure 13 and 14. Firstly, at the levels of sulfur and reactive elements present in the alloys studied, the solubility products should be exceeded in all of the alloys, i.e. all of the alloys should contain sulfides unless the oxygen content is high enough to precipitate oxides. Point (i.) is qualitatively consistent with observations that additions of Y to PWA 1484 (with 2 ppm S) which resulted in a $Y$ content of $2 \mathrm{ppm}$ had no effect on adherence while those which resulted in Y contents of $19 \mathrm{ppm}$ or greater produced dramatic improvements [29].

The results of Figure 13 and 14 are also consistent with studies in which alloys were intentionally doped with sulfur and reactive elements [25,30]. Smialek [30] found that a NiCrAl alloy doped with 1000 ppma $\mathrm{Zr}(0.15 \mathrm{wt} \%)$ and $1000 \mathrm{ppma} \mathrm{S}(0.054 \mathrm{wt} \%)$ showed extensive spalling which was essentially the same as that from undoped NiCrAl. If the solubility product of " $\mathrm{ZrS}$ " is close to $10^{-6}$, Figure 14 indicates the doped alloy would contain approximately $1 \mathrm{ppmw}(0.0001 \mathrm{wt} \%)$ of sulfur in solution, which is sufficient to cause spallings of the oxide. Similarly, alloys doped with 3000 ppma $\mathrm{Zr}(0.46 \mathrm{wt} \%)$ and $1000 \mathrm{ppma}$
$\mathrm{S}(0.054 \mathrm{wt} \%)$ or $1000 \mathrm{ppma} \mathrm{Zr}(0.15 \mathrm{wt} \%)$ and $100 \mathrm{ppma} \mathrm{S}(0.0054$ $w t \%)$ showed similar amounts of spalling which were much less than that for the undoped alloy. Figure 14 indicates that both of these alloys would have nearly the same amount of sulfur left in solution $\left(0.2 * 10^{-5} \mathrm{wt} \%\right.$ for $0.46 \mathrm{wt} \% \mathrm{Zr}$ and $2 * 10^{-5} \mathrm{wt} \%$ for $0.15 \mathrm{wt} \% \mathrm{Zr}$ ) and, therefore, similar levels of scale adherence. Luthra and Briant [25] compared sulfur contents in $\mathrm{NiCrAl}$ of $500(0.027 \mathrm{wt} \%)$ and $3000 \mathrm{ppma}(0.16 \mathrm{wt} \%)$ along with 0.1 at\% Y $(0.15 \mathrm{wt} \%)$. The alumina was adherent to the lower sulfur alloy but spalled severely from the higher sulfur alloy. If the solubility product of YS may be estimated as $10^{-10}$, Figure 13 indicates the alloy with good adherence had a negligible amount of residual sulfur while the higher sulfur alloy had a very high residual sulfur content. Therefore, for a given level of sulfur contamination anticipated, it should be possible to calculate the amount of a particular reactive element needed to reduce the residual sulfur content below some critical level which would prevent any sulfur-caused deterioration of alumina adherence. This has been done in Table 1. where, based on the

Table I Reactive Element Content Required for $\mathrm{C}_{\mathrm{S}}{ }^{0}=0.05$ ppma:

\begin{tabular}{|c|c|}
\hline \multicolumn{2}{|c|}{$\mathrm{K}_{\mathrm{SP}}=(\mathrm{at} \% \mathrm{M})^{*}(\mathrm{at} \% \mathrm{~S})=1 * 10^{-6}$} \\
\hline $\mathrm{CS}^{0}$ (ppma) & $\mathrm{C}_{\mathrm{M}^{0}(\mathrm{a} 1 \%)}$ \\
\hline 0.1 & 0.28 \\
\hline 1 & 0.28 \\
\hline 10 & 0.28 \\
\hline 50 & 0.28 \\
\hline 100 & 0.29 \\
\hline 500 & 0.33 \\
\hline 1000 & 0.38 \\
\hline \multicolumn{2}{|c|}{$\mathrm{K}_{\mathrm{SP}}=(\mathrm{at} \% \mathrm{M})^{*}(\mathrm{at} \% \mathrm{~S})=1^{*} 10^{-10}$} \\
\hline $\mathrm{C}_{\mathrm{S}}{ }^{0}$ (ppma) & $\mathrm{C}_{\mathrm{M}^{0}}(\mathrm{a} \mathrm{a} \%)$ \\
\hline 0.1 & 0.000005 \\
\hline 1 & 0.00001 \\
\hline 10 & 0.0001 \\
\hline 50 & 0.005 \\
\hline 100 & 0.01 \\
\hline 500 & 0.05 \\
\hline 1000 & 0.1 \\
\hline
\end{tabular}

above described experimental results, a critical sulfur content of 0.05 ppma ( $0.027 \mathrm{wt} \%$ ) was chosen. It will be noted that for the larger solubility product (thought to approximate additions of $\mathrm{Ti}, \mathrm{Zr}$, or $\mathrm{Hf}$ ) the amount of reactive element required is essentially independent of bulk sulfur content for those usually encountered (1-100 ppm) and remains high even for low amounts of sulfur. For the smaller solubility product (thought to approximate $Y$ additions) the amount of reactive element required is much less but varies with the amount of sulfur contamination. If accurate solubility products are obtained, such calculations should allow the choice of the optimum amount of reactive element doping without "overdoping" which can result in intermetallic phases which are detrimental to mechanical properties or large amounts of reactive element oxides in the scale. 
The improvement in the cyclic oxidation resistance of PWA 1484 by lowering the initial sulfur content is qualitatively consistent with the above calculations. Similarly, the improvement in Hf-doped superalloys by hydrogen-annealing, PWA 1484 in Fig. 2 and CMSX-4 in Ref. 20, may be expected from an effective lowering of $C_{S}^{o}$ by the anneal. However, Figure 14 indicates that the residual sulfur content, which would stand in equilibrium with "HfS", would not be lowered much by reducing $C_{S}^{0}$. The quantity which is lowered is $C_{S}^{M S}$ i.e. the amount of sulfide in the alloy. Therefore, the improvements in PWA 1484 and CMSX-4 may result from decreasing the amount of sulfur which can be released from sulfide as the alloy/oxide interface encroaches and the $\mathrm{Hf}$ is oxidized. Also, as illustrated in Figure 15 , the value of $C_{M}^{\text {Re sid }}$ increases continuously as $C_{S}^{o}$ decreases. Therefore, lowering the initial sulfur content of PWA 1484 will leave more $\mathrm{Hf}$ in solution to tie up sulfur that is released during oxidation and to tie up other potentially detrimental impurities.

This approximate analysis is deficient in that accurate values for the

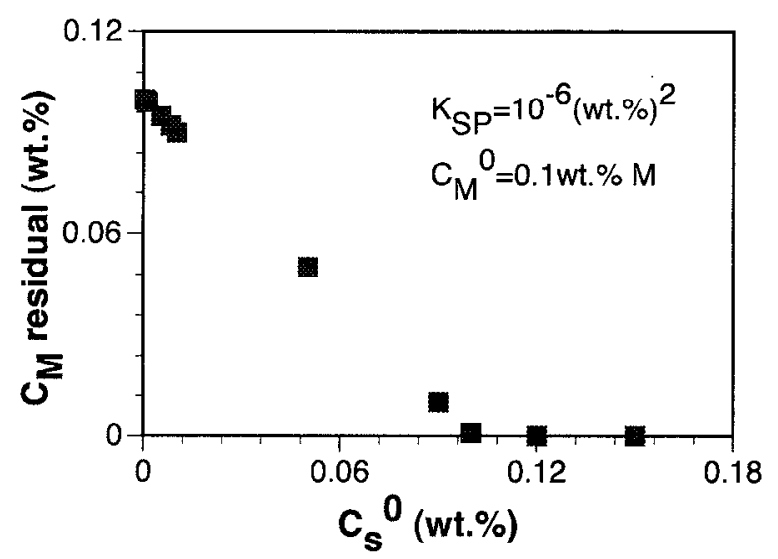

Figure 15: The concentration of reactive element (M) left in solution as a funtion of total sulfur content $\left(\mathrm{C}_{\mathrm{S}}^{0}\right)$ in the alloy.

solubility products are not known. For example, the results in Figure 5 would tend to indicate that the steep portion in the top diagram of Figure 13 and 14 should occur at less than $C_{s}^{u}=8$ ppmi.e the solubility product of hafnium sulfide in PWA 1484 is actually more than an order of magnitude grcatcr than the one used in Figure 14. Ilowever, it does indicate that evaluation of the sulfur-gettering capability of a given reactive element addition cannot be accomplished by a simple mass balance. The magnitude of $K_{S P}$ and how the equilibrium may be affected by other reactive components, particularly oxygen and carbon, must be considered along with the amounts of sulfur present and reactive element added. This type of analysis has also been shown to be qualitatively explain the effects of reactive elements and sulfur on the cyclic oxidation behavior of alumina-forming $\mathrm{FeCrAl}$ alloys [31].

\section{Liquid-Phase Desulfurization}

The above results indicate the improvement in alumina adherence which can be achieved by removing sulfur and the need to reduce the sulfur content to the range of 1 ppm or lower to take full advantage of this approach. Although sulfur can be removed from solid alloys by annealing in purified hydrogen, this technique is both slow and inefficient. Recently an experimental program has been initiated to attempt to remove sulfur in nickel and nickel-based alloys to below 1 $\mathrm{ppm}$ in the liquid state. If successful, this will allow economical removal of sulfur from commercial sized heats.

The technique used is to melt $10 \mathrm{lb}$. of nickel in a vacuum induction furnace and allow the sulfur in the nickel to react with a reactive lining. The reactions will be of the type:

$$
\begin{gathered}
\mathrm{MO}+\underline{\mathrm{S}}=\mathrm{MS}+\underline{\mathrm{O}} \\
\mathrm{MO}+\underline{\mathrm{S}}+\underline{\mathrm{C}}=\mathrm{MS}+\mathrm{CO} \\
\mathrm{M}_{2} \mathrm{O}_{3}+\underline{\mathrm{S}}=\mathrm{M}_{2} \mathrm{O}_{2} \mathrm{~S}+\underline{\mathrm{O}} \\
\mathrm{M}_{2} \mathrm{O}_{3}+\underline{\mathrm{S}}+\underline{\mathrm{C}}=\mathrm{M}_{2} \mathrm{O}_{2} \mathrm{~S}+\mathrm{CO}
\end{gathered}
$$

Under vacuum, the presence of carbon proceeding to form carbon monoxide will tend to push the reactions to the right. The presence of aluminum in the alloy would provide a similar impetus but would result in an oxide inclusion being formed. Thermodynamic calculations considering various active linings, such as $\mathrm{CaO}$ and $\mathrm{Y}_{2} \mathrm{O}_{3}$, indicate that it should be possible to remove the sulfur to well below the $1 \mathrm{ppm}$ level.

Experiments carried out so far indicate that sulfur is maintained at 1 ppm and that the mechanism appears to proceed to produce calcium metal which bubbles through the liquid alloy, as indicated by the following reaction.

$$
\mathrm{CaO}+\mathrm{C}=\mathrm{Ca}(\mathrm{g})+\mathrm{CO}
$$

The reaction with sulfur in this case will involve

$$
\mathrm{Ca}(\mathrm{g})+\underline{\mathrm{S}}=\mathrm{CaS}
$$

Experiments have not been carried out using $\mathrm{Y}_{2} \mathrm{O}_{3}$ linings and currently the vacuum furnace is being modified to allow metal samples for analysis to be taken during the run. This will allow mechanisms, kinetics, and limiting sulfur levels to be determined.

\section{Summary And Conclusions}

The results of this study have shown that desulfurization of aluminaforming $\mathrm{Ni}$-base superalloys and $\mathrm{NiAl}$ by hydrogen annealing can result in improvements in cyclic oxidation comparable to that achieved by doping with reactive elements.

It is possible to estimate the amount of sulfur available to segregate to the alloy/oxide interface and how this is influenced by reactive element additions or hydrogen annealing. If these calculations can be made more quantitative it should be possible to engineer alumina-forming alloys for optimum resistance to cyclic oxidation. Preliminary experiments to desulfurize Ni-base alloys in the liquid phase have been discussed. 


\section{Acknowledgement}

This work was supported by the University of Pittsburgh Materials Research Center, AFOSR Contract F49620-95-1-0167, C. Ward, monitor.

\section{References}

1. D. P. Whittle and J. Stringer, Phil. Trans. Roy. Soc. Lond., A295, (1980), 309.

2. J. Stringer, Met. Rev., 11 (1966), 113.

3. J. K. Tien and F. S. Pettit, Met. Trans., 3 (1972), 1587.

4. E. J. Felten, J. Electrochem Soc., 108 (1961), 490.

5. F. A. Golightly, F. H. Stott, and G. C. Wood, Oxid. Met., 10 (1976), 163.

6. H. Pfeiffer, Werkst. Korros., 8 (1957), 574.

7. J. E. McDonald and J. G. Eberhardt, Trans. TMS-AIME, 233 (1965), 512.

8. J. E. Antill and K. A. Peakall, J. Iron Steel Inst., 205 (1967),1136.

9. A. W. Funkenbusch, J. G. Smeggil, and N. S. Bornstein, Met. Trans., 16A (1985), 1164.

10. J. G. Smeggil, A. W. Funkenbusch, and N. S. Bornstein, Met. Trans., 17A (1986), 923.

11 B.K.Tubbs and J.K.Smialek, "Effect of Sulfur Removal on Scale Adhesion to PWA 1480" Symposium on Corrosion and Particle Erosion at High Temperatures, eds. V. Srinivasan and K. Vedula, TMS,(1989), 459.

12. "Oxidation of Low Sulfur Single Crystal Nickel-Base Superalloys", Superalloys 1992, eds.. S. D. Antolovich et sl.,. (TMS , 1992), 807.

13. J. C. Noyan and J. B. Cohen, Residual Stresses, (Springer Verlag 1987)

14.. C.S. Barrett et al., eds., Advances in X-Ray Analysis, vol. 135 (Plenum, 1992), 205-210.

15. C.S. Barrett et al, eds., Advances in X-ray Analysis, vol. 32 (1989), 285-292

16. B. D. Cullity, Elements of X-ray Diffraction, (2nd ed., Addison Wesley, Reading, MA, 1978).

17. J. L. Smialek, Met. Trans., 22A (1991), 739

18. J. L. Smialek et al, Thin Solid Films, 253 (1994), 285-292.

19. S. J. Wang and H. J. Grabke, Z. Metallk., 61 (1970), 597.

20. T. A. Kircher, A. Khan, and B. Pregger, cited in ref. 17.
21. Gilfrich et al, eds, Adances in X-Ray Analysis, vol, 37 (Plenum Press, New York, 1994), 189.

22. A.M.Huntz, J.L.Lubrun, and A.Boumaza, Oxid. Metals, 33 (1990), 321.

23. C.Diot, P.Choquet, and R.Mevrel, cited in ref.22.

24. M. Schutze, Ox. Metals. 44 (1995), 29.

25. K. L. Luthra and C. L. Briant, Oxid. Metals, 397 (1986), 26.

26. P. Y. Hou and J. Stringer, Oxid. Metals, 38 (1992), 323.

27. H. J. Suhmutzler, H. Viefhaus, and H. J. Grabke, Surf, Intcrface Anal, 18 (1992), 581.

28. "Thermo-Kinetic Analysis of Precipitation Behaviour of Ti Stabilized Interstitial Free Steel", in Interstitial Free Steel Sheet: Processing, Fabrication and Properties, eds. L. E. Collins and D. L. Baragar (Canadian Inst. of Mining, Metallurgy, and Petroleum, Ottawa, 1991), 15.

29. P. R. Aimone and R. L. McCormick, "The Effects of Yttrium and Sulfur on the Oxidation Resistance of an Advanced Single Crystal Nickel Based Superalloy", Superalloys 1992, eds. S. D. Antolovich et al., (TMS , 1992), 817.

30. J. L. Smialek, "The Effect of Sulfur and Zirconium Co-doping on the Oxidation of NiCrAl", in High Temperature Materials Chemistry IV, ed. Z. A. Munir, D. Cubicciotti, and H. Tagawa, (The Electrochem Soc., 1987), 24.

31. G. H. Meier, F. S. Pettit, and J. L. Smialek, Materials and Corrosion, 46 (1995), 232. 